\section{Hæmagglutination induced by Nucleic Acids}

Precipitation of some protein particles, induced by nucleic acids due to the interaction phenomenon between these two components in certain conditions, has attracted the attention of numerous workers, especially of cellular biochemists. However, very little is known concerning the interaction between nucleic acids and biological corpuscles, such as blood cells and bacteria. except for the serological reports ${ }^{1}$ of hæmagglutination of tanned erythrocytes coated with DNA by reacting with some antibody in sera of systemic lupus erythematodes. Experiments were therefore carried out to elucidate the general effects of nucleic acids-yeast RNA and sperm DNA, regardless of their species specificity-on erythrocytes.

The buffered salines $(0 \cdot 147 \mathrm{M}$ sodium chloride containing $0.02 \mathrm{M}$ citric acid-sodium citrate buffer solution in the range of $6 \cdot 0-4 \cdot 0$ ) are used as the diluents of this experiment. The $p \mathrm{H}$ of each nucleic acid solution $(0 \cdot 1$ per cent) is adjusted with $0.2 \mathrm{~N}$ sodium hydroxide and diluted with stock solution of buffered sodium chloride, so as to bring its final ionic concentrations the same as the diluents. To nucleic acid solutions with two-fold serial dilution, the same volume of 2.5 per cent human erythrocytes solution, washed and resuspended in diluent, is added in the test-tube and incubated for $15 \mathrm{~min}$ at $25^{\circ} \mathrm{C}$. The results, that is, the degree of hæmagglutination reactions, are read macro- and micro-scopically, which are shown in Table 1. Erythrocytes, which are pretreated with trypsin, exhibit the conspicuous rise of nucleic acidinduced agglutination avidity, but not any change of agglutination titres of nucleic acids. The remarkable changes of agglutination titres of nucleic acid by applying different individual human erythrocytes are not found. Agglutination activity of nucleic acid solution can be absorbed with the erythrocytes. For example, $1 \mathrm{ml}$. of diluted RNA (dilution $1: 8$, that is, $25 \mathrm{\gamma} / \mathrm{ml}$.) is completely absorbed with the same volume of 2.5 per cent erythrocytes solution $\left(5 \times 10^{8} / \mathrm{ml}\right.$.), showing that RNA molecules over $1.8 \times 10^{6}$ can be fixed on the surface of one erythrocyte, assuming that the molecular weight of yeast RNA is $17 \times 10^{3}$ and Avogadro's number $6 \times 10^{23}$.

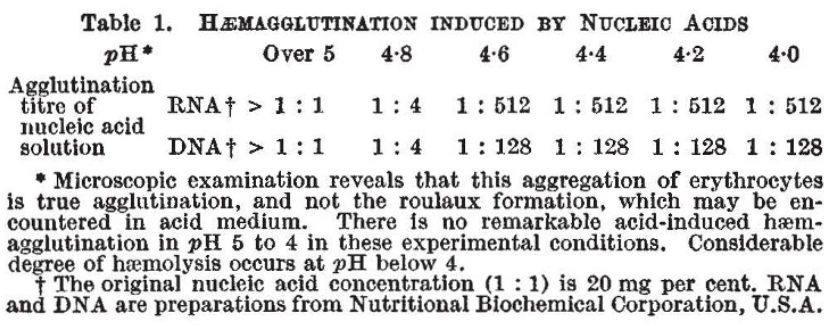

Addition of sera ( $p H 4.5)$ of human, rabbit, sheep and guinea pig inhibits this nucleic acid-induced hæmagglutina tion. As for the proteins, so far tested, human albumin shows this inhibitory action, while $\alpha$-globulin, which is precipitated at $p H \mathbf{H} \cdot \mathbf{5}$, has no effect on this hæmagglutination. Erythrocytes of sheep, guinea pig and rabbit are agglutinated by nucleic acids also. (Both proteins were fractionated by Cohn's fractionation technique of human plasma proteins.)

From these results it is not so difficult to suppose that there are some receptors on the surface of erythrocytes, more generally on the protoplasmic membrane of erythrocytes, which can combine with nucleic acids to agglutinate them. The phenomenon that some proteins, such as ovo- ${ }^{2,3}$ and human-albumin ${ }^{4}$, can interact with nucleic acids in $p \mathrm{H}$ below isoelectric point of the former ones is attractive in the analysis of this reaction mode. It is reasonable to expect that certain proteins, which possess the isoelectric point at about $p H 4 \cdot 6$, are determining receptors in this agglutination. In the same way, inhibition of this agglutination due to the presence of human blood albumin can be elucidated by the affinity of albumin for nucleic acids, so that it may deprive nucleic acid-erythrocytes complex of nucleic acid as a competitor. It is also possible that hæmagglutination induced by some viruses may be attributed to their main components, that is, their nucleic acids or nucleoproteins. Further studies on the nature of receptors of erythrocytes are now in progress.

Department of Legal Medicine, University of Tokyo, Hongo, Tokyo.

${ }^{1}$ Miescher, P., and Strässle, R., Vox Sang., 2, 283 (1957).

2 Machebœuf, M., and Tayeau, F., Bull. Soc. Chim. Biol., 23, 31, 49 (1941). 'Tayeau, F., C.R. Acad. Sci., Paris, 212, 575 (1941).

- Delage, B., Bull. Soc. Chim. Biol., 18, 1304, 1600, 1603 (1936).

\section{PATHOLOGY}

\section{Pathology of the Effect of the Laser Beam on the Skin}

THE effect of the laser on the eye has been known since the work of Zaret ${ }^{1,2}$. The effect on the skin is not well known ${ }^{3,4}$. Previously, some physicists have reported subjectively no effects at all or only a slight pricking sensation of the skin ${ }^{2}$.

The laser used for these preliminary experiments was a solid type with ruby crystal. The crystal has a diameter ot $\frac{1}{4}$ in. and a length of 2 in. with a crystal optic axis of $90^{\circ}$. The emission is $6943 \AA$ with a minimum energy input of 100 joules $(2 \cdot 0 \mathrm{kV})$. Reflectivity is $99+$ to 90 per cent. Output at 400 joules input equals 0.84 joule. (Maser Optics, Inc., Boston, Massachusetts.) The laser head was mounted on an optical bench with an external lens system. Lenses used chiefly were a single convex lens with a focal length of $10.2 \mathrm{~cm}$, a double convex with a focal length of $6.0 \mathrm{~cm}$ and a double convex with a focal length of $1 \cdot 2 \mathrm{~cm}$. A centring disk and also a special mount were used on the optical bench to hold the area to be exposed. A red light was attached to the head to aid in centring the beam. Protective glasses were used by operating personnel.

The skin specimens examined included white skin of rabbits and man, coloured skin of animals and man, pigmented baso-squamous papillomas (so-called seborrhœic keratoses), superficial hæmatomas in the skin of man, white skin of man covered with lamp black, indian ink, tars, and

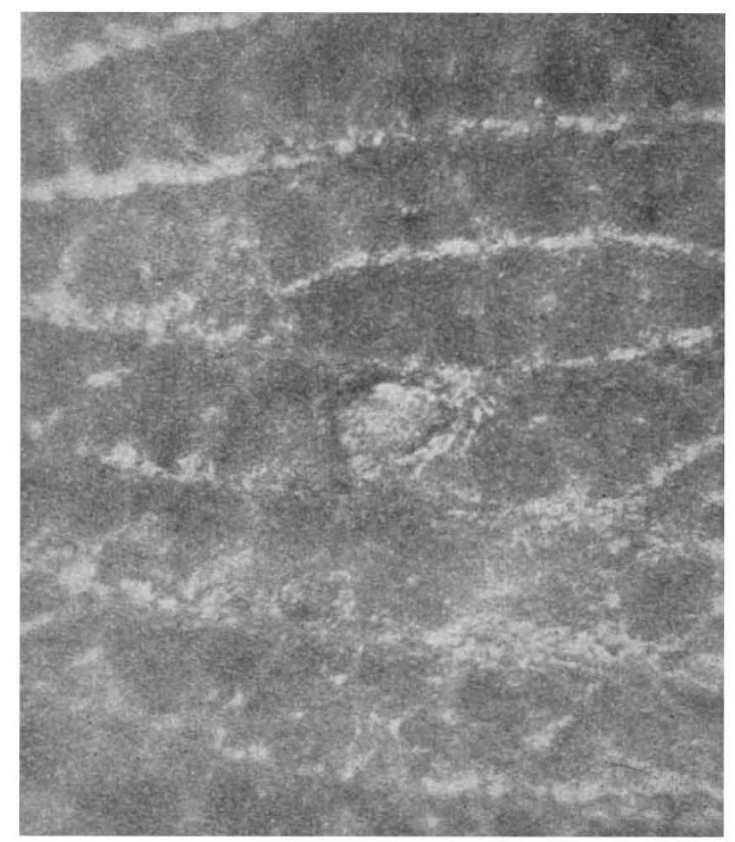

Fig. 1. Surface of skin of palm coloured by dihydroxyacetone and exposed to laser. Superficial crusted area is the area of impact (black-
and-white picture from 'Kodachrome', $\times 50$ ) 